\title{
LA ASISTENCIA SANITARIA MATERNAL E INFANTIL EN ESPAÑA
}

El progreso sanitario de los pueblos modernos, que tan notablemente han reducido la cifra de mortalidad general y prolongado la duración media de la vida, ha tenido en España pareja repercusión.

El mejor tenor de vida, motivado especialmente por el desarrollo y aplicación en la mayor parte de los pueblos de las conquistas de la moderna higiene pública, ha hecho dar un paso de gigante en la iucha contra enfermedades evitables como nunca hubiérase conseguido con medidas de higiene individual. Estas, no obstante, debidas al progreso cultural del pueblo español, son también factores positivos de gran valor en el progreso sanitario de España.

"E? índice de la cultura y prosperidad de un pueblo-se ha dicho-lo constituye su cifra de mortalidad infantil." ¿Qué ocurre en España a este respecto?

Llámase cifra de mortalidad infantil al número de niños que mueren en ei primer año de la vida por cada 1.000 nacidos vivos. Pues bien, al comienzo del siglo actual la mortalidad infantil en España era ảe 200. Desaparecían entre cada 1.000 niños nacidos vivos 200 antes de su primer cumpleaños. Esa espantosa ciŕra llegó en 1935 (último año normal en el orden demográfico) a 109. El avance fué extraorolinario. Posteriormente, como acurre siempre con motivo de guerras o revoluciones, la cifra empeoró, notándose actuaimente tendencia a mejorar de ruevo en los últimos años.

Mas no en todas las regiones españolas los hechos son tan hala§26 güeños. 


\begin{tabular}{|c|c|c|c|c|c|c|c|}
\hline & 1931 & morían & en & Las Palmas. & 214 & por & 10 \\
\hline & $"$ & $"$ & $"$ & Zamora ..... & 207 & $"$ & \\
\hline " & $"$ & $"$ & $"$ & Cáceres . . . . . . . . & $20 \Xi$ & $"$ & \\
\hline$"$ & $"$ & $"$ & $"$ & Padajoz . . . . . . . . & 192 & $"$ & $"$ \\
\hline$"$ & $"$ & $"$ & $"$ & Cuenca . . . ...... & 189 & $"$ & 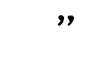 \\
\hline " & $"$ & $"$ & $"$ & Sa’amanca ... & 185 & $"$ & $"$ \\
\hline " & $"$ & $"$ & $"$ & Segovia . . . & 172 & $"$ & " \\
\hline$"$ & $"$ & $"$ & $"$ & Tererife $\ldots \ldots \ldots$ & $3.7 \AA$ & " & " \\
\hline & $"$ & $"$ & $"$ & Valladolid . . . ...... & 170 & $"$ & $"$ \\
\hline & $"$ & $"$ & $"$ & Avila & 169 & $"$ & $"$ \\
\hline & " & $"$ & $"$ & León & 168 & $"$ & \\
\hline
\end{tabular}

Contrastando con provincias de muy baja mortalidad infantil, como:

\begin{tabular}{|c|c|c|c|}
\hline Castellón . . . . . & & por & \\
\hline Baleares & 71 & $"$ & \\
\hline Guipúzcoa . . . . . . . & 73 & $"$ & \\
\hline Valencia . . . ....... & 73 & $"$ & \\
\hline Barcelona . & 76 & $"$ & \\
\hline
\end{tabular}

Gráficamente vemos representado ese fenómeno demográfico en el mapa adjunto, que repręenta la mortalidad infantil en 1937.

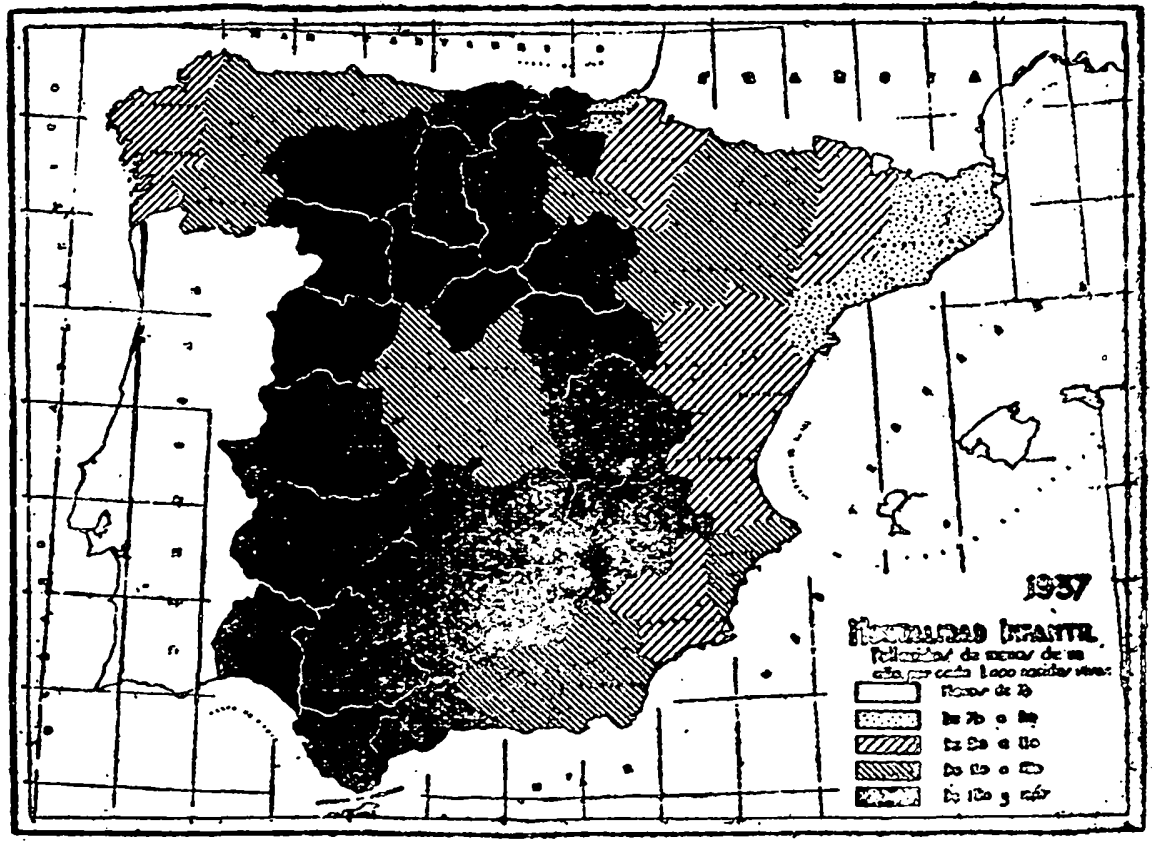


¿Qué posición ocupa España en relación con otros países?

Situación intermedia entre naciones que todavía sobrepasan la cifra de 200 por 1.000 (U. R. S. S., Chile, Hungría, Rumanía, etc.) y las que alcanzan cifras envidiables, como Holanda, Nueva Zelanda, Suecia, Noruega, etc.

¿Podrá mejorar nuestra cifra de mortalidad infantil? Probablemente, pues aparte de circunstancias inevitables, como son raza, clima, costumbres, etc., que nos separan de algunos países, ¿qué razón hay para que la mortalidad infantil sea mayor entre nosotros que en Francia e Italia?

Probablemente la cultura sanitaria de dichos países, unida a una organización sanitaria más perfecta, reduce las enfermedades, como ocurrió en España en los últimos cincuenta años. Luchemos, pues, contra la ignorancia, contra la incultura sanitaria, hagamos que toda madre deseche los errores de la sabiduría popular y salvaremos millares de vidas de niños españoles.

A pesar del lastre que supone para el progreso demográfico de España su mortalidad infantil, aumenta nuestra población de modo sorprendente gracias a su fecundidad y natalidad.

En la mayor parte de los países europeos la natalidad, de 35 por 1.000 (35 nacimientos cada 1.000 habitantes), ha bajado en cincuenta años alrededor de 15 por 1.000 (Inglaterra, Francia, Alemania).

España se mantuvo con natalidad de 25 a 30 por 1.000 , y aún hoy (a pesar de la crisis universal) es de 20 por 1.000. Gracias a ello la población española creció desde 18 a 25 millones de habitantes en medio siglo.

La natalidad y mortalidad infantil en diferentes poblaciones civilizadas queda expresada en el siguiente gráfico: 


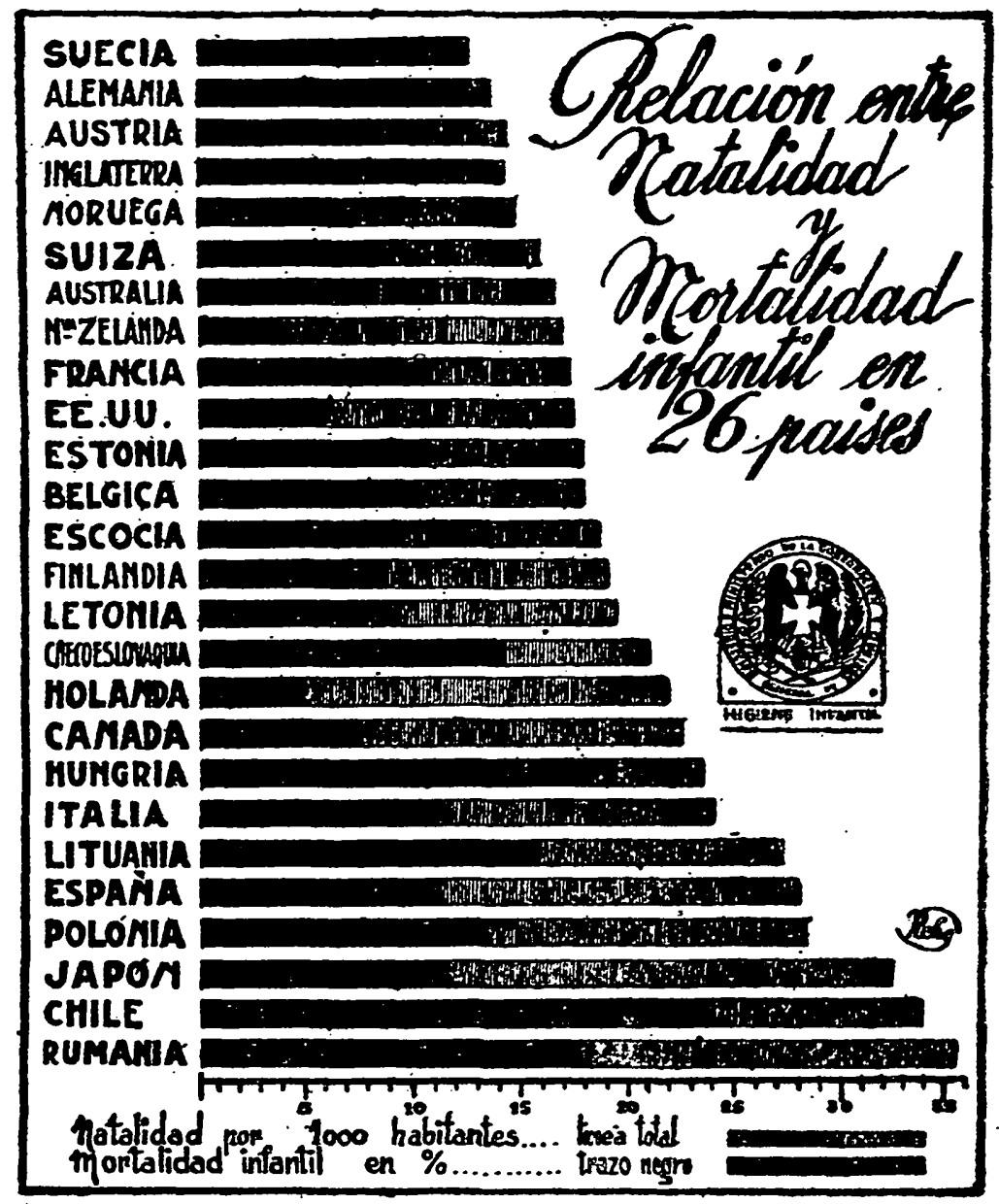

Han existido siempre en España instituciones de protección a la infancia, creadas corrientemente por el espíritu cristiano y caritativo de nuestro pueblo, faltas tal vez de matiz técnico sanitario.

En 1904 aparece en España la primera Ley de Protección a la Infancia. Al calor á la misma créanse varios Institutos o Centros de Asistencia Infantil.

Como tantos preceptos legales, perfectos (aún hoy es copiada por muchas legislaciones), dicha Ley no se cumplió íntegramente, dejando de rendir la eficacia apetecida.

El desarrollo de la vida municipal y provincial dió lugar a la creación de algunos notables Institutos de Sanidad y Medicina Infantil. Creáronse Gotas de Leche, mejoráronse algunas Inclusas o Casa Cuna. En honor a la verdad hemos de manifestar que las Gotas de 529 
Leche atendieron a los niños como Centros de Beneficencia, actuando, como en frase vulgar se ha dicho, de "lecherías gratuitas", fomentando muchas veces la lactancia artificial, y no como verdaderos Centros sanitarios por falta de vigilancia a cargo de especialistas pediatras puericultores. Hay que convertirlas en dispensarios de Puericultura y seleccionar rigurosamente su personal médico si queremos rindan eficacia.

Comentarios semejantes sugieren las Inclusas a cargo de Diputaciones provinciales. Centros de recogida de niños, sin condiciones higiénicas muchas de ellas, sin personal especializado, tienen muy elevada mortalidad infantil. Aparte de mejorarles técnicamente, sobre todo en cuanto a personal se refiere, precisa convertir dichos Centros en casa maternales de recogida de madres en peligro de abandonar a su hijo. Protejamos al niño a través de la madre y evitemos su abandono, tan peligroso en el orden moral, político y sanitario.

En 1925 creáronse las Escuelas de Puericultura de Madrid (recordemos con cariño al profesor Suñer, su fundador, y a los Generales Primo de Rivera y Martínez Anido) y las de Valencia, Sevilla, Bilbao y Gijón. Prepárase el personal técnico, mejora la cultura médica en el campo de la Pediatría y se hace posible la creación de los servicios de Puericultura del Estado en todos los Institutos provinciales de Sanidad y poco después en los Centros de Higiene Rural, dependientes de la Dirección general de Sanidad.

Para aminorar los efectos nefastos del trabajo femenino en orden a la maternidad y cumpliendo el compromiso contraído por España en Washington (1919), estableció el subsidio y luego el Seguro de Maternidad, encargándose de regirle el Instituto Nacional de Previsión. Mediante servicios de asistencia domiciliaria primero y después en los dispensarios clínicas de la Obra Maternal e Infantil, el Instituto Nacional de Previsión prodiga la asistencia sanitaria en embarazo, parto y puerperio de las obreras y de sus hijos en el primer año.

Para luchar contra la miseria nació durante el Movimiento $\mathrm{Na}$ cional la Institución de Auxilio Social.

Para extender a las mujeres obreras, aunque ellas no trabajen, estos beneficios, se promulgó la Ley de 18 de julio de 1942, y finalmente, en diciembre del mismo año aparece la Ley del Seguro Obligatorio de Enfermedad, cuya implantación tantos beneficios ha de reportar en el orden sanitario.

530 Hay que señalar en el campo de la maternología y puericultura el 
hecho más notable de los últimos años: la promulgación de la Ley de Sanidad Infantil y Maternal de 12 de julio de 1941. En ella se aspira, y no dudamos ha de conseguirse, a coordinar el esfuerzo de cuantas instituciones dependientes de diferentes organismos se ocupan de vigilar o asistir a la madre o al niño en sus diversas edades, encuadrạ́ndolas en un plan nacional de obras de maternología y puericultura.

Nuestro mejoramiento demográfico, motivado especialmente por la lucha contra enfermedades evitables, particularmente en la infancia, no ha conseguido todavía colocarnos junto a países con población relativa alta. Indudablemente nuestro territorio requiere una población mayor. Por ello ha dicho el Caudillo: "Día llegará en que nuestra Patria alcance la cifra de 40 millones de habitantes, a los que puede mantener dignamente merced a sus grandes recursos".

\footnotetext{
Dr. Juan Bosch Marf́n Jefe de los Servicios de Puericultuss del Estado
} 